\title{
Application of Artificial Neural Network (Ann) In Operation of Reservoirs
}

\author{
S.S.Khare ${ }^{1}$, Dr. A.R.Gajbhiye ${ }^{2}$ \\ I. S.S.Khare, Assistant Engineer-II, Regional Training Centre, WRD, Nagpur \\ 2. Dr. A.R.Gajbhiye, Professor \& Head of Department, Department of Civil Engineering, Yeshwantrao Chavan \\ College of Engineering, Nagpur.
}

\begin{abstract}
Reservoir operation is an important element in water resources planning and management. It consists of several parameters like inflow, storage, evaporation and demands that define the operation strategies for giving a sequence of releases to meet the demands. The operating policy is a set of rules for determining the quantities of water to be stored or released or withdrawn from a reservoir or system of several reservoirs under various conditions. Reservoir operation frequently follows a conventional policy based on Guide curves (Rule curves) that prescribes reservoir releases based on limited criteria such as current storage levels, season and demands. Operating policies can be derived using system techniques such as simulation, optimisation and combination of these two. System analysis has proved to be a potential tool in the planning, operation and management of the available resources. In recent years, artificial intelligence techniques like Artificial Neural Networks (ANN) have arisen as an alternative to overcome some of the limitations of traditional methods. In most of the studies, feed forward structure and the back propagation algorithm have been used to design and train the ANN models respectively. Detail analysis will be carried out to develop an ANN model for reservoir operation and assess the application potential of ANN in attaining the reservoir operation objectives compared with the conventional rule curves.
\end{abstract}

Key words:Artificial Neural Network, Back propagation, Guide curves (Rule curves), optimisation,reservoir operation, simulation.

\section{Introduction}

Reservoir operation is an important element in water resources planning and management. It consists of several parameters like inflow, storage, evaporation and demands that define the operation strategies for giving a sequence of releases to meet a large number of demands from stake-holders with different objectives, such as irrigation, water supply, hydro power etc. Applying simulation and optimisation techniques for reservoir operation is not a new idea. Various techniques have been applied in an attempt to improve the efficiency of reservoir (s) operation. This technique includes Linear Programming (LP); Non liner Programming (NLP); Dynamic Programming (DP); Stochastic Dynamic Programming (SDP). In recent years Heuristic Programming such as Genetic Algorithms (GP), Fuzzy logic and Artificial Neural Networks (ANN) are emerging as an alternative to conventional techniques.

Hydraulic constraints are defined by the reservoirs continuity equation,

$\mathrm{S}(\mathrm{t}+1)=\mathrm{S}(\mathrm{t})+\mathrm{I}(\mathrm{t})-\mathrm{R}(\mathrm{t})-\mathrm{E}(\mathrm{t}), \mathrm{t}=1,2 \ldots \ldots \ldots \ldots \mathrm{T}$

Where, $S(t+1)$ is storage at time step $t+1$.,

$\mathrm{S}(\mathrm{t})$ is storage at time step $\mathrm{t} ; \mathrm{I}(\mathrm{t})$ is the reservoir net inflow at time step $\mathrm{t}$ (including reservoir inflow and precipitation) ; $\mathrm{R}(\mathrm{t})$ is the reservoir out flow at time step $\mathrm{t}$ and $\mathrm{E}(\mathrm{t})$ is the reservoir evaporation at time step $\mathrm{t}$. $\mathrm{T}$ is the total number of time steps in the considered period.

Constraint on out flow/releases defined by maximum and minimum permissible reservoir releases:

$$
\mathrm{R} \min \leq \mathrm{R}(\mathrm{t}) \leq \mathrm{R} \max \quad \mathrm{t}=1,2, \ldots \ldots \ldots \ldots \mathrm{T}
$$

Constraints on storages defined by maximum and minimum permissible reservoir storages

$\mathrm{S} \min \leq \mathrm{S}(\mathrm{t}) \leq \mathrm{S} \max \quad \mathrm{t}=1,2 \ldots \ldots \ldots \ldots \mathrm{T}$

Constraints on elevations defined by maximum and minimum permissible water level at specified sites/reservoirs;

$$
\mathrm{h} \min \leq \mathrm{h}(\mathrm{t}) \leq \mathrm{h} \max \quad \mathrm{t}=1,2, \ldots \ldots . \mathrm{T} .
$$

In general, a multi-objective reservoir operation problem can be formulated as follows

Maximise / Minimise F (x) = [ F1 (x), F2 (x) .........Fn(x)]

Subject to

qi $(\mathrm{x}) \leq 0 \quad \mathrm{I}=1,2, \ldots \ldots \ldots \mathrm{m}$

Where $F j(x), j=1,2, \ldots \ldots . . N$ are the objective functions, $X$ is a vector of decision variables, qi $(x)$ are constraints that define the feasible solutions. 


\section{Theoretical Background:-}

An Artificial Neural Network (ANN) is a massively parallel-distributed-information-processing system that has certain performance characteristics resembling biological neural network of human brain. An ANN consists of a number of neurons that are arranged in an input layer, an output layer and one or more hidden layers. The input neurons receive and process the input signals and send the output to other neurons in the network where this process is continued. This type of network where information passes one way through the network is known as feed forward network. Neurons response is usually sent to the other ones. A set of inputs in the form of input vector $\mathrm{X}$ is received by each unit and weights leading to the node form a weight vector $\mathrm{W}$. The inner product of $\mathrm{X}$ and $\mathrm{W}$ is net and the output of the node is $\mathrm{f}(\mathrm{net})$

net $=\mathrm{X} . \mathrm{W}=\sum \mathrm{Xi}$. Wi

out $=\mathrm{f}($ net $)$

$\mathrm{f}$ is called activation function whose functional form determines response of the node to the input signal it receives. Two functions are usually used in different applications: Sigmoid function and hyperbolic tangent, given as equation 3 and 4 respectively;

$\mathrm{f}(\mathrm{x})=1 /(1+\mathrm{e}-\mathrm{x})$

$\mathrm{f}(\mathrm{x})=(\mathrm{ex}-\mathrm{e}-\mathrm{x}) /(\mathrm{ex}+\mathrm{e}-\mathrm{x})$

A typical Artificial Neural Network is shown below.

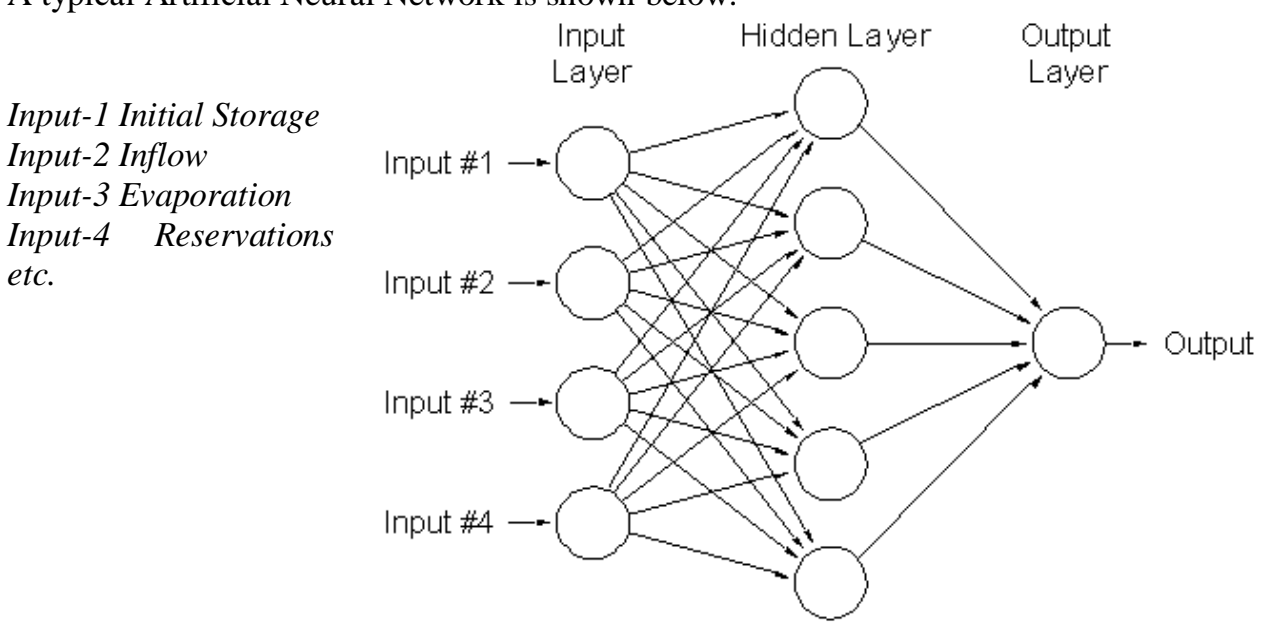

Output -Optimum

Release

As it is seen that each node in a layer is connected to all nodes in the previous layer (fully connected) and the output of the layer makes the input of the next one (feed forward). Sigmoid function and Back propagation algorithm (BP) are usually used. These types of networks are most common and are popularly known as Feed Forward Back Propagation ANN.

Training is a process by which the connection weights of an ANN are adapted through continues process of simulation of environment in which the net is embedded. In a supervised network training the network with the input and desired output should be provided. Initially, the network will produce the wrong answer. Error (difference between desired output and network output) will be used to adjust the weights (Back propagation). Training of networks is carried out in three steps: 1) Presenting training sets to input and output in neurons, 2) computation of the error of the network and back propagating it and 3) Adjusting weights in order to reduce the error. There are some learning rules based on BP algorithm and the most applicable one is Generalized Delta Rule. Weights are adjusted according to the equation 5 -

$\Delta w i j(n)=-\alpha \cdot d E / d w i j+n \cdot \Delta w i j(n-1)$

Where $\Delta$ wij(n) and $\Delta$ wij(n-1) are weight increments between node $i$ and $j$ during the $n$th and $(n-1)$ th pass or epoch. In this equation $\alpha$ and $\mathrm{n}$ are learning rate and momentum, respectively; and they are both useful for a better training process.

Several learning examples are presented to the ANN and when it has learned enough examples i.e. getting desired response, it is considered to be trained. After the learning cycles the weights are frozen. A set of data that the ANN has not encountered before is presented to validate its performance. Depending on the outcome either the ANN has to be retrained or it can be implemented for its designated use. Performance of a network is usually evaluated by some parameters such as 1) RMSE (root mean square error); 2) R-(correlation coefficient); 3) e- (relative error) all these parameters should be evaluated for both training and testing sets. In application of ANN to reservoir operation, preparation of train and test data is the first step. Initial storage, inflow forms input data whereas optimal release of reservoir forms output layer of ANN model. Dynamic programming model will be used for optimum operation policy of a reservoir and then simulation model presents the optimum monthly release of the reservoir over a considerable long period (preferably more than 35 years). Out of these data some represents train data and some represents test data of ANN model. The main 
objective of the reservoir system is water supply and irrigation, the objective function for DP will be minimising the sum of squared deficit ( SSD) which can be stated as equation 6;

Minimise $\mathrm{SSD}=\sum(\mathrm{R}(\mathrm{t})-\mathrm{D}(\mathrm{t}))^{2}$

And the restrictions are:

Continuity Eqn. $\mathrm{R}(\mathrm{t})=\mathrm{S}(\mathrm{t}+1)-\mathrm{S}(\mathrm{t})+\mathrm{I}(\mathrm{t})-\operatorname{loss}(\mathrm{t})$

Storage limitation : Smin $<\mathrm{S}(\mathrm{t})<\mathrm{Smax}$

Evaporation : $\operatorname{loss}(\mathrm{t})=\operatorname{Ev}(\mathrm{t})[\{\mathrm{A}(\mathrm{t})+\mathrm{A}(\mathrm{t}+1)\} / 2]$

Release : $\mathrm{R}(\mathrm{t})>0$

In these equations, $\mathrm{R}(\mathrm{t}), \mathrm{S}(\mathrm{t}), \mathrm{I}(\mathrm{t}), \mathrm{D}(\mathrm{t}), \operatorname{loss}(\mathrm{t})$, and $\mathrm{A}(\mathrm{t})$ are release, storage, inflow, demand, losses and reservoir area respectively.

Finally the structure of an ANN model will be constructed defining 1) the number of hidden layers and neurons in each layer, 2) selection of transformation function's type. Lastly supposing the method for acquiring optimum weight of the nodes, the final network will be implemented by trial and error.

\section{History}

Development of ANN has an interesting history. Major events / achievements in ANN history are presented here to appreciate how contributions to the field have led to its development over the years.

The year 1943 is often considered the initial year in the development of ANN systems; when W.S. McCulloch and W. Pitts proposed a theory of information processing based on networks of binary processing elements, called 'neurons'. The network differs from a traditional computer in that the steps of the program are not executed sequentially, but in parallel with 'neurons'. This model laid the foundation for future development. Main contributor in the development of ANN are Donald Hebb(1949), Minsky(1954), Frank Rosenblatt (1958), Bernard Widrow \& Marcian Hoff(1960), Nils Nilsson(1965), Sun Ichi Amari (1972,1977), Fukushima and Miyaka (1980), Tuevo Kohonen (1977, 1982, 1984, and 1988), James Anderson (1977), Kohonen (1982), Stephen Grossberg and Gail Carpenter (1974, 1982). Hopfield's work in 1982 \& 1984 is considered a breakthrough in neural network research. The publication by McClelland and Rumelhart opened a new era for the once underestimated computing potential of layered networks. The PDP group published their book Parallel Distributed Processing in 1986. There are numerous publications on neural networks. Most important articles that establish the foundation of neural networks can be found in two books edited by Anderson \& Ressenfield. The list of applications that can be solved by neural networks has expanded from small test size example to large practical tasks. Very large scale integrated neural network chips have been fabricated. Educational offering have been established to explore the artificial neural network science. Although ANN has had interesting history, the field is steel in its early stages of development.

\section{APPLICATION OF ANN IN RESERVOIR OPERATION:-}

Since the early 1990's there has been a rapidly growing interest among engineers \& scientist to apply ANN in diverse field of water resources engineering like forecasting of stream flows, river stage, rainfall, water table fluctuations, ground water modelling, water quality modelling, water management, reservoir operation and so on. Many studies are reported in the literature on the application of ANN in the field of water resources were in the field of stream flow and rainfall forecasting. Few studies have been concentrated on reservoir operation. In most of the studies, feed forward structure and the back propagation algorithm have been used to design and train the ANN models respectively. Important studies/papers related to the reservoir operation studies using ANN are listed in the following paragraphs.

Jain, Das and Shrivastava(1999) used artificial neural network for reservoir inflow prediction and the operation for upper Indravati Multipurpose Project, Orissa. They developed two ANN to model the reservoir inflows and to map the operation policy. They found that ANN was suitable to predict high flows. They concluded that ANN was a powerful tool for input output mapping and can be used effectively for reservoir inflow forecasting \& operation. Raman and Chandramouli (1996) used artificial neural networks for deriving better operating policy for the Aliyer dam in Tamil Nadu. General operating policies were derived using neural network model from the DP model. The results of ANN with dynamic programming algorithm provided better performance than the other models. Chandramouli et al (2002), Cancelliere et all (2002), Oscar Dollins and Eduardo Varas (2004), Haddad and Alimohammadi (2005), Farid Sharifi, Omid Haddad and Mahsoo Naderi (2005), Paulo Chaves and Toshiharu Kojiri (2007), Paulo Chaves \& Fi John Chang (2008), Yi min Wang at all (2009) , Amir Ali Moaven Shahid (2009,Paresh Chandra Deka and V. Chandramouli (2009), El Shafie A at all (2011), Sabah S Fayaed at all (2011), Dr.Bithin Datta (2012), T. S. Abdulkadir at all (2012) are among the others successfully studied the application of ANN in optimal operation of reservoir system. They concluded and recommended that forecasting using ANN is very versatile tool in reservoir operation. 


\section{OBJECTIVES OF THE RESEARCH WORK:-}

The proposed research work will be carried out with respect to the following objectives:

- To use the data for training Artificial Neural Network model.

- To test the Artificial Neural Network model.

- To compare the results of conventional rule curves with the results of Artificial Neural Network model.

"It can be summarised that the main objective of this study will be to develop and assess the application potential of the Artificial Neural Network in attaining the reservoir operational objectives compared with the conventional rule curves."

\section{CASE STUDY :-}

To develop and assess the application potential of the Artificial Neural Network model in attaining the reservoir operational objectives compared with the conventional rule curves one major irrigation project "Lower Wunna project" of Nagpur district is taken as a case study. Lower Wunna project envisages two storages one across Wunna river near village Wadgaon and one across Nand river near village Sadeshwar in Umred tahasil of Nagpur district. This is a multipurpose project and is intended to cater the irrigation as well as domestic snd industrial water demands of the nearby area. The Wadgaon storage has two main canals one on each bank where as the Nand storage has one main canal which serves as a feeder to Left bank canal of Wadgaon storage.

Index map of Lower Wunna Project

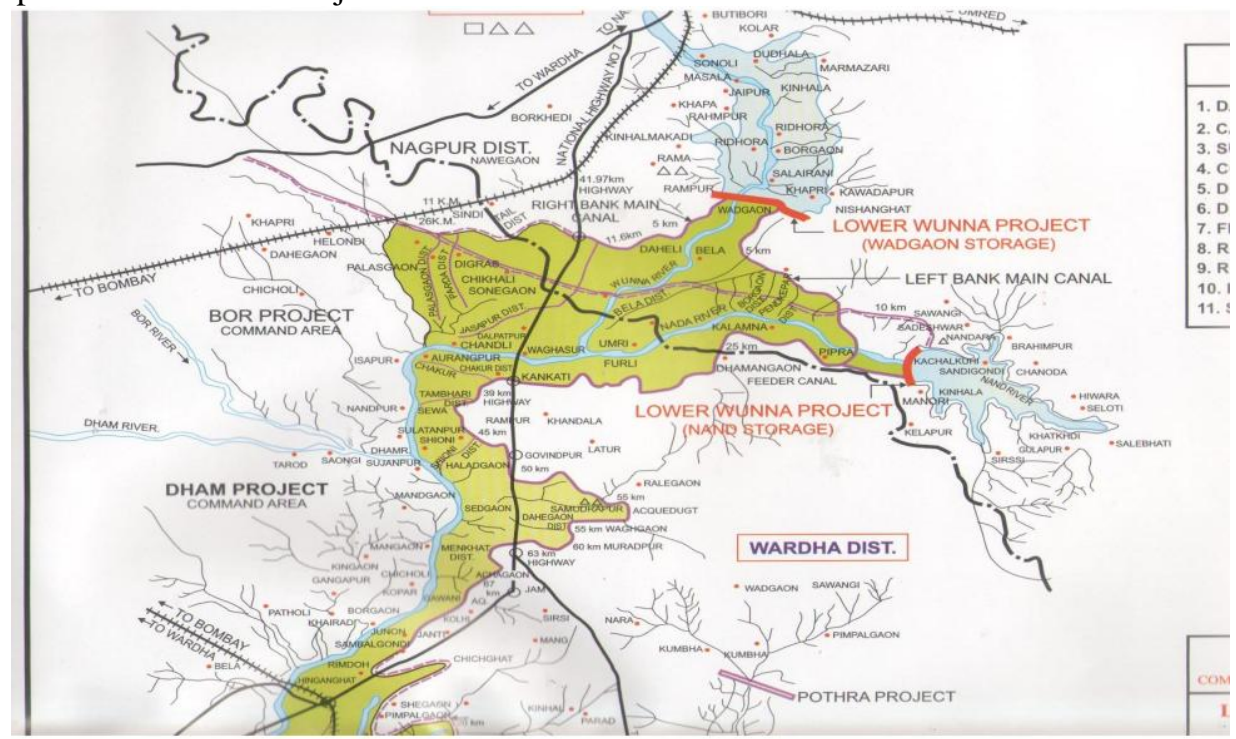

Salient features of Lower Wunna Project

\begin{tabular}{|l|l|l|l|}
\hline Sr.No. & Particulars & Wadgaon Storage & Nand Storage \\
\hline 1 & $\begin{array}{l}\text { Location } \\
\text { Village/Tahasil/Districr }\end{array}$ & Wadgaon/Umred/Nagpur & Sadeshwar/Umred/Nagpur \\
\hline 2. & River :- & $\begin{array}{l}\text { Wunna a tributary of Wardha } \\
\text { River }\end{array}$ & $\begin{array}{l}\text { Nand a tributary of Wunna } \\
\text { river }\end{array}$ \\
\hline 3. & Catchment area :- Gross/Free & $1076 \mathrm{Sq} . \mathrm{Km} . / 846 \mathrm{Sq} . \mathrm{Km}$. & $398 \mathrm{Sq} . \mathrm{Km} . / 398 \mathrm{Sq} \cdot \mathrm{km}$. \\
\hline 4. & Avg. Annual Rainfall & $1200 \mathrm{~mm}$ & $1200 \mathrm{~mm}$ \\
\hline 5. & $\begin{array}{l}\text { Water availability :- } \\
\text { i) at } 75 \% \text { dependability }\end{array}$ & $\begin{array}{l}232.50 \mathrm{Mm}^{3} \\
139.10 \mathrm{Mm}^{3}\end{array}$ & $68.30 \mathrm{Mm}^{3}$ \\
& ii) at $90 \%$ dependability & $\mathrm{Mm}^{3}$ \\
\hline 6. & Storage capacity :- Gross / Live & $152.60 / 136.00 \mathrm{Mm}^{3}$ & $62.18 / 53.20 \mathrm{Mm}^{3}$ \\
\hline 7. & Annual Water demand :- & $292.80 \mathrm{Mm}^{3}$ & \\
\hline
\end{tabular}

Reservoir operation schedule for monsoon months i.e. storage building phase as per conventional Guide Curve method is prepared for both the reservoirs for $75 \%$ and $90 \%$ dependable available water. The guide curves are prepared only for monsoon season and indicates the storage built up pattern. It does not give the storage depletion in non-monsoon months.

The graphical representation of the guide curves are given below. 

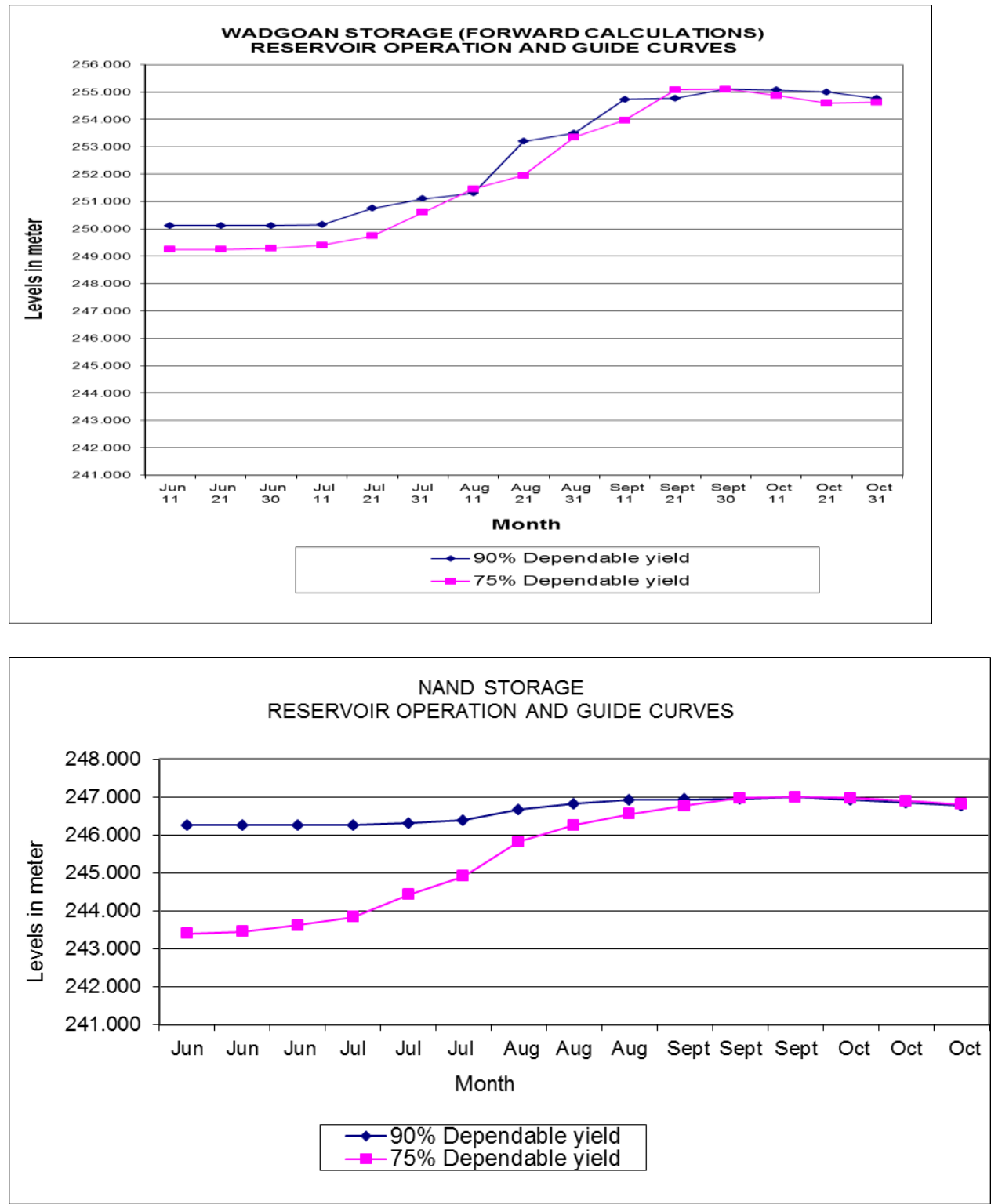

This provides general operation strategies for reservoir releases according to the current reservoir level, hydrological conditions, water demands and the time of the year.

Lower wunna project is in the vicinity of New Nagpur and MIHAN. Presently the main purpose of this project is to cater the irrigation demands. However new Nagpur and MIHAN in particular is rapidly developing as an commercial and industrial hub. This will give substantial rise to non-irrigation demands in near future. Lower Wunna project being the only assured source of water the conflict between irrigation and non-irrigation demands are bound to increase. Established rule curves, however, do not allow a fine tuning and hence optimisation of the reservoir operations in response to changes in the prevailing conditions with ANN model is possible.

Artificial neural networks technology is still very new and is developing quickly. The most likely applications of neural networks is to simulate physical systems that are best expressed by parallel networks involving classification, association and reasoning rather than sequential arithmetic computing. Water resources engineering especially prediction of inflows and the optimal operation of reservoirs is one of the most promising application of ANN. An attempt will be made to develop artificial neural network model for reservoir operations and assess the application potential of the Artificial Neural Network in attaining the reservoir operational objectives compared with the conventional rule curves. 


\section{References:-}

[1]. S.K.Jain, A. Das \& S.K.Shrivastava (1999), "Application of ANN for reservoir inflow prediction \& operation", Journal of Water planning and management, ASCE.

[2]. V.Chandramouli and H.Raman (2001), "Multireservoir modelling with dynamic programming and neural networks", Journal of Water planning and management, ASCE.

[3]. Farid Sharifi, Omid Bozorg \& Mahsoo Naderi (2005), "Reservoir optimal operation using dynamic programming and Artificial Neural Network ", Proceeding of sixth WSEAS Int. Conf. on evolutionary computing, Lisbon, Portugal.

[4]. Paulo Chaves and Toshiharu Kojiri (2007),"Stochastic Fuzzy Neural Network: Case Study of Optimal Reservoir Operation", Journal of Water Resources Planning and Management, ASCS.

[5]. Paulo Chaves \& Fi-John Chang (2008),"Intelligent reservoir operation system based on evolving Artificial Neural Networks", Journal of Advances in Water Resources.

[6]. Amir Ali Moaven Shahidi (2009),"Evaluation of combined model of DP and Neural Networks in single reservoir operation", Journal of Applied Sciences Research.

[7]. Paresh Chandra Deka and V. Chandramouli (2009),"Fuzzy Neural Network modelling of Reservoir Operation, Journal of Water Resources Planning and Management, ASCS.

[8]. Dr.Bithin Datta (2012),"Application of ANN real time optimal operation of multireservoir system, Journal of Water Resources Planning and Management. 